\title{
Does Electromagnetic Radiation affect drug stability?
}

\author{
Subramani Parasuraman', Krishnamoorthy Venkates Kumar ${ }^{2}$ \\ 'Editor-in-Chief, Journal of Young Pharmacists, AIMST University, Jalan Bedong-Semeling, 08100 Bedong, Kedah, MALAYSIA. \\ ${ }^{2}$ Pharmaceutical Technology, Faculty of Pharmacy, AIMST University, Jalan Bedong-Semeling, 08100 Bedong, Kedah, MALAYSIA. \\ E-mail: jypeditor@gmail.com \\ DOI: 10.5530/jyp.2018.10.1
}

Stability is one of the key determinant in assessing the quality, safety and efficacy of Active Pharmaceutical Ingredient (API) or Finished Pharmaceutical Product (FPP). Stability issues in a pharmaceutical products could result in physical, chemical changes in the finished products. Such degraded products could lead to treatment inefficiency, development of mild to severe adverse reactions in consumer, monetary loss and regulatory noncompliance. The stability of any API or FPP could be influenced by temperature, humidity, direct sun light, changes in storage conditions, frequency of single unit dispensing from bulk package, and other radiation related factors. Temperature is one of the key physical factors which affects drug stability and potency. For example, storage of insulin at $32^{\circ} \mathrm{C}$ and above lose its potency after two weeks and on cold storage retains its potency for more than three weeks. ${ }^{1}$ Few of the pharmaceutical formulations are advised to store it in amber colour containers to prevent its degradation by direct sun light. It should be observed that the radiation related factors are expected to play a major role in affecting the stability of FPPs. The radiation related factors includes radiation from cellular towers, smart phones, mobiles, Wi-Fi supporting devices, electronic gadgets, particle radiation, acoustic radiation and gravitational radiation may also affect the stability of FPP. The effects of radiation gains much significance specifically in the current digital world, because the digital devices have become a part of our daily routine life. The effect of various radiation factors on the stability of APIs or FPPs is a major area of health concern that has to be given due importance. The current guidelines on stability assessments have not incorporated the effects of these radiations on APIs or FPPs. It is essential to study the effect of radiations on stability of any formulation to ensure it's safety.

Radiation is normally classified as ionizing and non-ionizing radiation. The effects of ionizing radiation such as sun light, X-rays, and gamma rays on pharmaceuticals are well studied as compared to non-ionizing radiation. Non-ionizing radiation is a part of EMR which is produced by both natural and artificial sources with frequency range between $3 \mathrm{kHz}$ and $300 \mathrm{GHz}$. Non-ionizing electromagnetic field radiation has been widely used to accelerate wound healing, in cancer treatment and dental applications. ${ }^{2}$ However, the long-term effect of non-ionizing electromagnetic radiation on any biological or any physical system is not completely explored. Few studies suggested that, rodents that are exposed to to longterm EMR radiations are developed motor coordination impairment. ${ }^{3.4}$ EMR radiations also known to enhance carcinogenesis, induce genetic mutations and causes teratogenicity. ${ }^{2}$

EMR may not interfere with stability of pharmaceutical formulation on short-term basis, but it may cause minimum of oxidation reaction on long-term exposure and this free radical may affect the drug's stability. In last few decades, use of recombinant biological products for therapeutic purposes, had increased enormously and they may face greater risk with EMR radiation. If such recombinant biological products on exposure ionizing/ non-ionizing radiation during storage period could change its

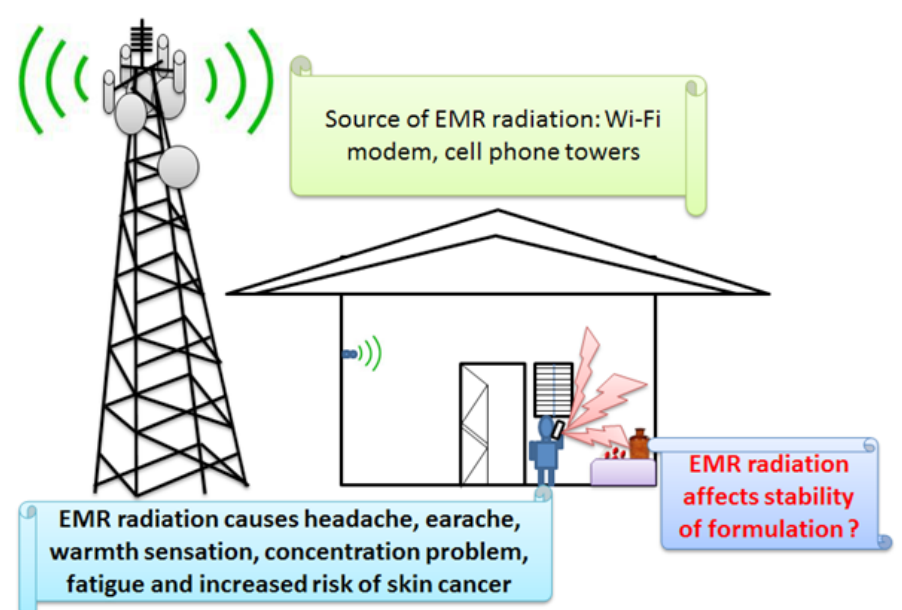

Figure 1: What will be effect of long-term exposure of electromagnetic Radiation on drug stability?.

protein structure, alter its efficiency and eventually lead to potential adverse effects in biological systems.

Recent study suggests that radiofrequency electromagnetic radiation (RF-EMR) from mobile phones could cause adverse health effects that include headache, earache, warmth sensation, concentration lapse increased risk of skin cancer. ${ }^{5}$ Odac1 et al., studied the effect of EMR radiation on rodents and reported that, the 32-day-old female rat offspring on exposure with $900 \mathrm{MHz}$ EMR affected the development of Purkinje cells in it's cerebellum. ${ }^{6}$ Nguyen et al., studied the effect of radiation from cardiac computed tomographic angiography (CTA) and suggested that, exposure of $>7.5 \mathrm{mSv}$ causes DNA damage, which is associated with programmed cell death. ${ }^{7}$ These studies indicates the magnitude of EMR radiation related effects on biological system. The same reaction could be expected in immunopharmaceuticals, leading to protein denaturation, loss of potency and efficiency.

In current global scenario, utilization of digitalized gadgets had occupied a permanent place in human life and these effects are further fuelled by huge rise in digital innovations and technological advances around the globe. It should also be observed that the radiation emitted by utilization of all these digitalized gadgets are expected to have a strong impact on human health as well as pharmaceuticals. It is imminent to study the effect of non-ionizing radiation on APIs and FPPs that may help us to ensure the delivery of stable and safe medications for the current and future generations. The long-term exposure of electromagnetic Radiation on drug stability is unclear (Figure 1); hence extensive are required to understand the effect of radiation on drug stability. 


\section{REFERENCES}

1. Vimalavathini R, Gitanjali B. Effect of temperature on the potency \& pharmacological action of insulin. Indian J Med Res. 2009;130(2):166-9.

2. Kostoff RN, Lau CGY. Modified Health Effects of Non-ionizing Electromagnetic Radiation Combined with Other Agents Reported in the Biomedical Literature. In: Geddes C. (eds) Microwave Effects on DNA and Proteins. Springer, Cham. 2017; 97-157.

3. Sakhnini L, Al-Ghareeb S, Khalil S, Ahmed R, Ameer AA, Kamal A. Effects of exposure to $50 \mathrm{~Hz}$ electromagnetic fields on Morris water-maze performance of prenatal and neonatal mice. J Association of Arab Unv Basic Appl Sci. 2014;15:1-5;

4. Parasuraman S, Kah Yee SW, Chuon BL, Ren LY. Behavioral, biochemical, and pathological alterations induced by electromagnetic radiation in Sprague-Daw- ley rats. BLDE Univ J Health Sci. 2016;1(1):61-3

5. Mortazavi SA, Tavakkoli-Golpayegani A, Haghani M, Mortazavi SM. Looking at the other side of the coin: the search for possible biopositive cognitive effects of the exposure to $900 \mathrm{MHz}$ GSM mobile phone radiofrequency radiation. J Environ Health Sci Eng. 2014;12(1):75

6. Odacı E, Hancı H, İkinci A, Sönmez OF, Aslan A, Şahin A, et al. Maternal exposure to a continuous $900-\mathrm{MHz}$ electromagnetic field provokes neuronal loss and pathological changes in cerebellum of 32-day-old female rat offspring. $J$ Chem Neuroanat. 2016:75(Pt B):105-10

7. Nguyen PK, Lee WH, LiYF, Hong WX, Hu S, Chan C, et al. Assessment of the Radiation Effects of Cardiac CT Angiography Using Protein and Genetic Biomarkers. JACC Cardiovasc Imaging. 2015;8(8):873-84.

Article History: Submission Date : 20-12-2017; Revised Date : 05-01-2018; Acceptance Date : 14-01-2018.

Cite this article: Parasuraman S, Kumar KV. Does Electromagnetic Radiation affect drug stability?. J Young Pharm. 2018;10(1):1-2. 